\section{Right Ventricular Function in Systemic Sclerosis-associated Pulmonary Arterial Hypertension}

\section{To the Editor:}

We read with interest the article "Tricuspid annular plane systolic excursion is a robust outcome measure in systemic sclerosis-associated pulmonary arterial hypertension" by Mathai, et $a l^{1}$. This excellent article describes the current need for a more detailed investigation of the right ventricle (RV). The authors clearly state that there is a need for a detailed evaluation of RV function measurements, e.g., the tricuspid annular plane systolic excursion (TAPSE), in a population with systemic sclerosis-associated pulmonary arterial hypertension $(\mathrm{SSc}-\mathrm{PAH})^{1}$.

Forfia, et $a l^{2}$ have also described the excellent sensitivity, reproducibility, and clinical utility of the TAPSE in various forms of PAH. For the convenience of readers and especially for centers performing detailed echocardiographic investigations of the RV, we add that our group has published normal TAPSE values for pediatric and adolescent patients ${ }^{3}$. In addition, we have described decreased TAPSE values for pediatric patients with PAH secondary to congenital heart diseases (PAH-CHD) ${ }^{4}$. We thank the authors for addressing the need for careful and systematic evaluation of the RV, especially in patients with different forms of PAH.

RV function should be carefully investigated in patients with systemic diseases known to influence the RV function and diseases that can lead to secondary PAH, including many rheumatologic disorders. RV function should also be investigated in patients with $\mathrm{CHD}$ and primary PAH. We hope that with more available normal reference values for this population that quantification of RV function in PAH will become easily available to all sonographers.
MARTIN KOESTENBERGER, PhD, MD, Division of Pediatric Cardiology, Department of Pediatrics, Medical University Graz, Graz, Austria; WILLIAM RAVEKES, MD, Division of Pediatric Cardiology, Johns Hopkins University School of Medicine, Baltimore, Maryland, USA. Address correspondence to Dr. M. Koestenberger, Department of Pediatrics, Medical University Graz, Auenbruggerplatz 30, A-8036 Graz, Austria. E-mail: Martin.Koestenberger@medunigraz.at or koestenbergerm@gmx.at

\section{REFERENCES}

1. Mathai SC, Sibley CT, Forfia PR, Mudd JO, Fisher MR, Tedford $\mathrm{RJ}$, et al. Tricuspid annular plane systolic excursion is a robust outcome measure in systemic sclerosis-associated pulmonary arterial hypertension. J Rheumatol 2011;38:2410-8.

2. Forfia PR, Fisher MR, Mathai SC, Housten-Harris T, Hemnes AR, Borlaug BA, et al. Tricuspid annular displacement predicts survival in pulmonary hypertension. Am J Respir Crit Care Med 2006;174:1034-41.

3. Koestenberger M, Ravekes W, Everett AD, Stueger HP, Heinzl B, Gamillscheg A, et al. Right ventricular function in infants, children and adolescents: Reference values of the tricuspid annular plane systolic excursion (TAPSE) in 640 healthy patients and calculation of z score values. J Am Soc Echocardiogr 2009;22:715-9.

4. Koestenberger M, Nagel B, Avian A, Ravekes W, Sorantin E, Cvirn $\mathrm{G}$, et al. Systolic right ventricular function in children and young adults with pulmonary artery hypertension secondary to congenital heart disease and tetralogy of Fallot: Tricuspid annular plane systolic excursion (TAPSE) and magnetic resonance imaging data. Congenit Heart Dis 2012;7:250-8.

J Rheumatol 2013;40:1; doi:10.3899/jrheum.120966 